\title{
ANALYSIS OF REPEATABILITY ON VIDEOGRAMMETRY FOR INFANTS' CRANIAL DEFORMATION
}

\section{ANÁLISIS DE REPETIBILIDAD EN VIDEOGRAMETRÍA PARA LA EVALUACIÓN DE LA DEFORMACIÓN CRANEAL EN NIÑOS}

\author{
Inés Barbero-García ${ }^{\mathrm{a},{ }^{*}}$, José Luis Lerma ${ }^{\mathrm{a}}$, Ángel Marqués Mateu ${ }^{\mathrm{a}}$, Pablo Miranda \\ ${ }^{a}$ Photogrammetry \& Laser Scanning Research Group (GIFLE), Department of Cartographic Engineering, Geodesy and \\ Photogrammetry, Universitat Politècnica de València, Cmno Vera, 46022, Valencia, Spain. inbargar@topo.upv.es; illerma@cgf.upv.es; \\ amarques@cgj.upv.es \\ ${ }^{\text {b }}$ Hospital Universitari i Politècnic/Instituto de Investigación Sanitaria La Fe, Avenida Fernando Abril Martorell, Valencia, Spain \\ mirandalloret@gmail.com
}

\begin{abstract}
:
Cranial deformation affects a large number of infants. The methodologies commonly employed to measure the deformation include, among others, calliper measurements and visual assessment for mild cases and radiological imaging for severe cases, where surgical intervention is considered. Visual assessment and calliper measurements usually lack the required level of accuracy to evaluate the deformation. Radiological imaging, including Computed Tomography (CT) and Magnetic Resonance Imaging (MRI), are costly and highly invasive. The use of smartphones to record videos that can be used for three-dimensional (3D) modelling of the head has emerged as a low-cost, noninvasive methodology to extract 3D information of the patient. To be able to analyse the deformation, a novel technique is employed: the obtained model is compared with an ideal head. In this study we have tested the repeatability of the process. For this purpose, several models of two patients have been obtained and the differences between them are evaluated. The results show that the differences in the ellipsoid semiaxis for the same patient are usually below $4 \mathrm{~mm}$, although they increase up to $6.4 \mathrm{~mm}$ in some cases. The variability in the distances to the ideal head, which are the values used to evaluate deformity, reaches a maximum value of $2.7 \mathrm{~mm}$. The errors obtained are comparable to those of classical measurement techniques and show the potential of the methodology in development.
\end{abstract}

Keywords: Photogrammetry, Low-cost, Plagiocephaly, 3D modelling

\section{Resumen:}

La deformación craneal afecta a un elevado porcentaje de lactantes, a pesar de esto, no existen estándares para su medición. Existen diversas metodologías empleadas para el análisis de este tipo de deformación, que van desde el análisis visual o la medición con calibre en casos leves, a pruebas radiológicas en casos más graves, en los que se plantea la posibilidad de una intervención quirúrgica. El análisis visual y la medición con calibre a menudo carecen de la precisión requerida para evaluar la deformación, mientras que las pruebas radiológicas (Tomografía Axial Computarizada, TAC, o Resonancia Magnética, RM) son altamente invasivas y tienen un alto coste. Otras soluciones como la fotografía tridimensional (3D) incluyen complejos sistemas de varias cámaras, lo que también supone un coste elevado. La posibilidad de utilizar videos tomados con teléfonos inteligentes para la creación de modelos 3D craneales se ha convertido en una posibilidad para obtener información 3D del paciente de forma precisa y con un coste bajo. Para analizar la deformación se ha planteado una metodología que consiste en calcular las distancias entre el modelo generado y una forma craneal ideal. En este estudio se ha llevado a cabo el análisis de la repetibilidad del proceso de obtención del modelo y de la cabeza ideal ajustada, para ello se han obtenido varios modelos 3D de dos pacientes y se han evaluado las diferencias entre ellos. Los resultados muestran unas diferencias en los semiejes de los elipsoides de aproximadamente $4 \mathrm{~mm}$, aunque este error llega a incrementarse hasta $6.4 \mathrm{~mm}$ en algunos casos. La variabilidad en las distancias del modelo a la cabeza ideal, empleadas para medir la deformidad tienen un máximo de $2.7 \mathrm{~mm}$. Las precisiones obtenidas con esta metodología son comparables a las obtenidas mediante técnicas de análisis tradicionales y muestran el potencial de la metodología en desarrollo.

Palabras clave: Fotogrametría, Bajo coste, Plagiocefalia, Modelado 3D

\section{Introduction}

Cranial deformation includes several conditions and pathologies that affect a large percentage of infants. The most common condition is deformational plagiocephaly (DP) which is caused by positional factors. The number of children affected by this type of deformation increased drastically after 1990 as a consequence of the American Academy of Pediatrics campaign "Back to Sleep". The

"Corresponding Author: Inés Barbero-García, inbargar@topo.upv.es 
campaign recommended supine sleeping position in order to prevent Sudden Death Syndrome and it spread to many countries (Pathmanaban et al. 2016).

Other types of deformation are caused by premature closing of the cranial sutures, which is known as craniosynostosis.

In most cases, the effects of the deformational plagiocephaly are aesthetical and can be corrected by active repositioning or the use of orthotic helmets (Schaaf et al. 2010). In contrast, craniosynostosis, which can cause major problems such as elevated intracranial pressure, usually requires surgical intervention for its correction.

Several methodologies are used for the analysis of cranial deformation including: visual assessment, caliper measurements, flexicurve, moulding devices, 3D photography and radiological imaging (Siegenthaler, 2015).

Despite of the different methodologies in use there are no standards for the measurement of the deformation. (Szpalski et al., 2011). For mild cases, deformation is usually evaluated by visual assessment or using calipers but experts disagree on the effectiveness of these methodologies.

For severe cases, especially when surgical intervention is needed, radiological imaging is used. Radiological imaging (Computed Tomography or Magnetic Resonance Imaging) is considered the most accurate method to extract 3D measurements of the skull. However, this methodology has important disadvantages. It is highly invasive as, due to the age of the patients, it is necessary the use of anaesthesia to put the patient to sleep. The use of radiation is also to be avoided in infants. Moreover, the methodology is costly, as it requires very specific equipment (Moghaddam et al. 2014).

There is a need for a non-invasive, accurate methodology that allows the correct evaluation of the deformation and the effectiveness of the different treatments (Plank et al. 2006).

$3 \mathrm{D}$ modelling is considered an interesting option as it is accurate and non-invasive. The main problem of the method is the acquisition of well-focused images in real clinical conditions, as the infants are usually in constant movement during the medical consultation (Schaaf et al. 2010). To deal with this issue complex setups of professional cameras or combinations of camera and laser are used. Due to the equipment employed, the method is costly.

The possibilities of a low-cost, non-invasive, smartphone based photogrammetric tool for cranial deformation analysis are presented in other studies (Barbero-García et al. 2017). Slow-motion videogrammetry recorded with a smartphone allows the quick acquisition of wellfocused images of the moving infants in real clinical conditions. Moreover, no special equipment or lighting conditions are required. The images are later used to create $3 \mathrm{D}$ models for analysis of cranial deformation in an accurate, repeatable, low-cost and non-invasive way.

Barbero-García et al. (2017) presented the calculation of differences to an ideal head, represented by an adjusted three-axis ellipsoid. The methodology has been pointed as an interesting option for cranial deformation, but its accuracy and repeatability are still being studied.

In this study, we evaluate the repeatability in the achieved 3D models. For this purpose, we have compared different models and ellipsoids of two different patients, obtained from different videos and from different frame selection.

\section{Methodology}

Two patients were studied, for each one several 3D models and fitted ellipsoids were obtained. The distances between the models and the fitted ellipsoids, used to calculate the deformation, were calculated and compared.

The ellipsoids were compared in two different ways. Firstly, the differences in the semiaxis were evaluated. Secondly, the whole set was registered and the distances between them were calculated (Fig. 1).

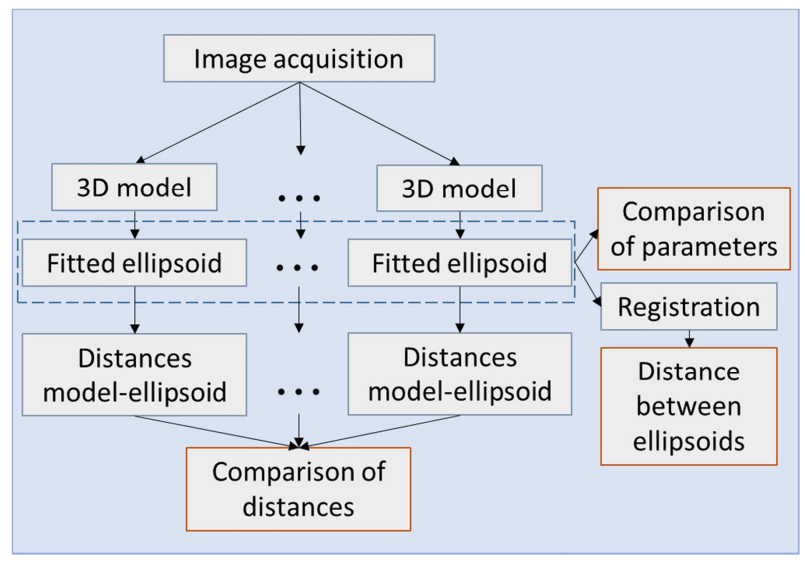

Figure 1: Methodology workflow.

\subsection{Image acquisition}

The video recording was carried out using a Smartphone Samsung Galaxy S7 with a resolution of 1280 x 738 pixels, $235 \mathrm{fps}$. Each video was recorded in less than a minute. No special lighting conditions and no tripod were required. The conditions were those of the doctor's office or the operating theatre.

A cap was placed on the patients head to avoid the effect of hair and provide some texture to facilitate the 3D modelling. Some coloured targets were also added.

Two patients were taken into account for this study. For the first patient three videos were recorded with different conditions: (1) with the patient lying, (2) with the patient standing (with help of an adult) and (3) under anaesthesia, in the operating theatre. For the second patient only one video, in the operating theatre, was taken.

All the videos were recorded during the same day, prior to the surgery to correct the cranial deformation of the patients.

The videos were later processed to extract the set of images used for modelling. The images were extracted automatically using a fixed frequency and bad-focused images were removed. Every set contained between 75 and 221 images. 


\subsection{Model creation}

Once the images were extracted, they were processed with the software PhotoScan (Agisoft, Russia). The process consisted of three steps: (1) Image alignment, (2) Point cloud densification and (3) Mesh creation. In some cases, texture was added only for visualization purposes. After its creation, every model was visually checked for completeness.

A total of four models were created for patient one, including one for each of the first two videos and two for the third video. For patient two, eight models were created using different sets of images from the same video.

\subsection{Ellipsoid fitting}

The fitted ellipsoid is proposed as the representation of the ideal cranial shape. An adjustment of the ellipsoid is carried out using Least Square Adjustment (Bektas 2015). The norm L2 is used. The semiaxis of the adjusted ellipsoid can be extracted from the conical parameters. Finally, the best-adjusted ellipsoid is obtained for each 3D model (Fig. 2).
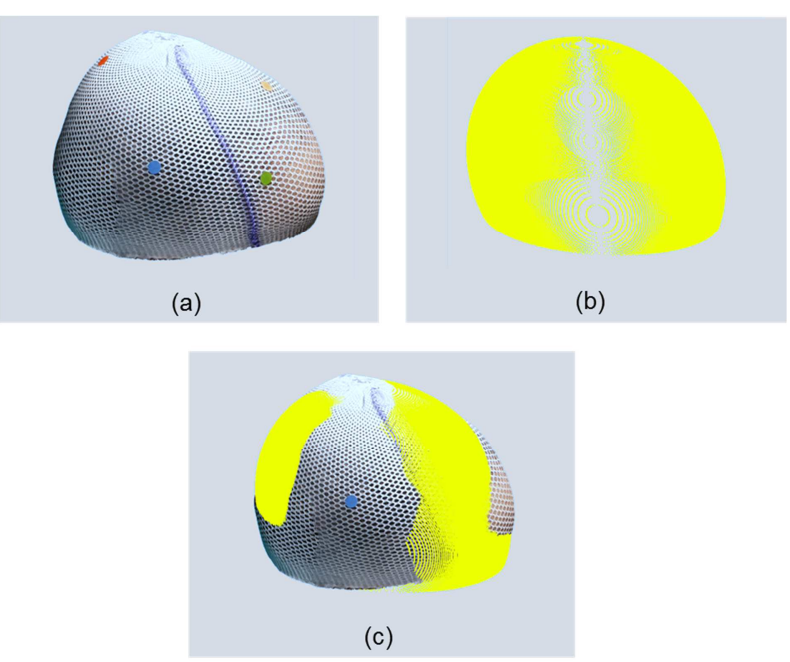

Figure 2: Ellipsoid fitting: a) 3D model; b) Ellipsoid; c) Overlaying model and ellipsoid.

\subsection{Distances from the ellipsoid}

The cranial deformation will be quantified as distances from the ellipsoid (Fig.3). The orthogonal distances, are therefore, calculated for every point of the model using the equations presented by Bektas (2014).

\section{Results}

Table 1 shows the results for patient one. In it, we can see the results of four different models created using different sets of images. The first set of images was extracted from a video taken with the patient lying. The second set was taken with the patient standing uphold. The last two sets were extracted from the same video, with the patient under anaesthesia. The number of images per model vary from 75 to 165 .

The semiaxis of the adjusted ellipsoids show differences up to $6.4 \mathrm{~mm}$. The largest difference is found between the last video and the others. The largest difference between video 1 and 2 is $1.9 \mathrm{~mm}$ while the largest difference between the two models created using the third video is $1 \mathrm{~mm}$.

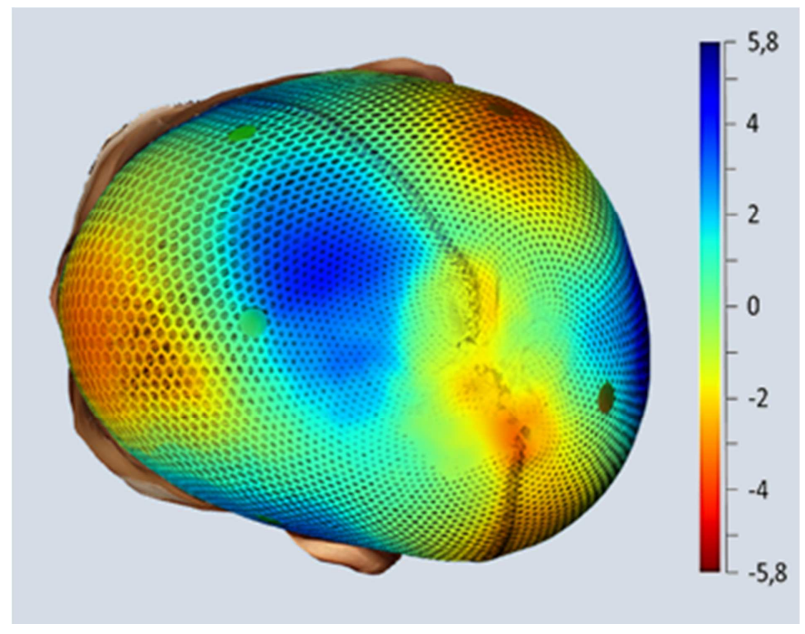

Figure 3: Distances to the ellipsoid represented as bathymetric colours (mm).

The distances to the adjusted ellipsoid, show a maximum difference between models of $3.3 \mathrm{~mm}$. Especially important for the deformation analysis would be variability, given the standard deviation, for this parameter the largest difference is $0.5 \mathrm{~mm}$.

The results for the second patient are shown in Table 2 and 3 . The largest difference for the ellipsoid parameters is $3.8 \mathrm{~mm}$. The differences in the distances to the ellipsoid are up to 1.6, with a maximum difference in the standard deviation of $0.2 \mathrm{~mm}$. For the patient the distances between each ellipsoid and a reference one are also shown, the largest difference, $2.7 \mathrm{~mm}$, is in the maximum distance.

Correlation between the number of images and the error was not found for any of the patients.

\section{Discussion}

This work studies the repeatability in the 3D models achieved and its fitted ellipsoid. The study is focused on the particular case of cranial deformation analysis where the robustness of the methodology is vital to consider it an option in real clinic conditions.

The differences in the calculation of the semiaxis are near to $3 \mathrm{~mm}$ in many cases, with an exceptional value of $6.4 \mathrm{~mm}$ for one semiaxis when different videos with different image acquisition conditions were compared. However, these error values are smaller for the comparison of distances from head to ellipsoid and in the comparison of distance from ellipsoid to ellipsoid.

Most important errors were registered when different videos were compared. This fact is, probably, due to the difference in image acquisition conditions. It was found that taking the images with the infant lying (video 1, patient 1) was not a good approach as the cap will fold and move as the infant changes position during the process. If this video is excluded, maximum difference in distances to the ideal ellipsoid is lower than $3 \mathrm{~mm}$. 
Table 1: Ellipsoid parameters and distances to the adjusted ellipsoid for patient one ( $\mathrm{mm})$.

\begin{tabular}{c|c|c|c|c|c|c|c|c|c} 
& Number of images & \multicolumn{3}{|c}{ Ellipsoid parameters } & \multicolumn{3}{c}{ Distances to the fitted ellipsoid } & \multicolumn{2}{c}{ Conditions } \\
& & Semiaxis 1 & Semiaxis 2 & Semiaxis 3 & Mean & Std & Max. & Min. & \\
\hline Video 1 & 140 & 60.9 & 68.8 & 97.9 & -0.4 & 2.3 & 6.4 & -9.3 & Patient lying \\
Video 2 & 109 & 59.8 & 68.6 & 96 & -0.4 & 2.4 & 5.6 & -6.4 & Patient standing \\
Video 3 Set 1 & 95 & 59.2 & 75 & 96.9 & -0.3 & 2 & 5.7 & -7.7 & Under anaesthesia \\
Video 3 Set 2 & 221 & 59 & 74 & 96.8 & -0.3 & 1.9 & 4.7 & -6 & Under anaesthesia
\end{tabular}

Table 2: Ellipsoid parameters, distances to the adjusted ellipsoid and distances for patient two ( $\mathrm{mm}$ ).

\begin{tabular}{c|c|c|c|c|c|c|c|c} 
& Number of images & \multicolumn{3}{|c|}{ Ellipsoid parameters } & \multicolumn{3}{c}{ Distances to the fitted ellipsoid } \\
& & Semiaxis 1 & Semiaxis 2 & Semiaxis 3 & Mean & Std & Max. & Min. \\
\hline Set 1 & 136 & 64.1 & 78.2 & 90 & -0.3 & 2.5 & 6.7 & -7.5 \\
Set 2 & 146 & 63.7 & 77.3 & 90.2 & -0.2 & 2.5 & 6.4 & -7.2 \\
Set 3 & 165 & 63.5 & 77.9 & 90.5 & -0.3 & 2.6 & 5.8 & -7 \\
Set 4 & 138 & 65.5 & 79.5 & 92.5 & -0.3 & 2.6 & 6.5 & -7.6 \\
Set 5 & 125 & 63 & 76.6 & 88.7 & 0.2 & 2.4 & 5.1 & -6.8 \\
Set 6 & 114 & 63.7 & 77.2 & 89.4 & -0.3 & 2.4 & 6.5 & -7 \\
Set 7 & 118 & 64.9 & 78.8 & 91.5 & -0.3 & 2.6 & 6.6 & -7.6 \\
Set 8 & 75 & 64.6 & 78.6 & 90.1 & -0.3 & 2.5 & 5.6 & -6.9 \\
Maximum difference & & 2.5 & 2.9 & 3.8 & 0.5 & 0.2 & 1.6 & 0.8
\end{tabular}

Table 3: Distances between each fitted ellipsoid and the one set as reference for patient two $(\mathrm{mm})$.

\begin{tabular}{c|c|c|c|c} 
& Mean & Std & Max. & Min. \\
\hline Set 1 & REF & REF & REF & REF \\
Set 2 & $-0,3$ & 0,4 & 0,5 & -2 \\
Set 3 & $-0,3$ & 0,4 & 0,4 & $-1,7$ \\
Set 4 & 0,8 & 0,8 & 2,9 & $-1,2$ \\
Set 5 & $-0,6$ & 0,7 & 1 & $-2,6$ \\
Set 6 & $-0,3$ & 0,4 & 0,4 & $-2,2$ \\
Set 7 & 0,4 & 0,6 & 1,6 & $-1,3$ \\
Set 8 & $-0,2$ & 0,4 & 0,2 & -2 \\
All models & $-0,07$ & 0,53 & 2,90 & $-2,60$
\end{tabular}

The number of images varied considerably among models but no relationship was found between this number and the obtained differences. Indeed, models with higher differences such as the one obtained for set 7 of patient two have an intermediate number of images (138). This fact may be explained because the number of images is always redundant and all the models are complete.

Cranial deformation is usually measured using callipers. These tools have a maximum precision of $1 \mathrm{~mm}$ in ideal conditions although the error in the identification of the cranial landmarks has to be added. According to this, an average error of $3 \mathrm{~mm}$ in the presented methodology makes it comparable to traditional methods. The amount of useful data obtained by $3 \mathrm{D}$ modelling is much larger.
With a caliper 3 to 8 measures are usually obtained, whereas 3D models have an average of 30.000 points and show the whole head.

In other studies, the error in cranial landmarks coordinates using much more costly 3D photogrammetric equipment was found to be up to $4 \mathrm{~mm}$ (Aldridge et al. 2005)

Furthermore, it has been found that differences in the area represented in the model affect greatly the results. For this reason, it is important to define correctly the area of the head that should be taken into account, excluding the neck and the face of the infant. This can be easily done by placing the cap correctly and taking into account only the area covered by it.

Other improvements should be tested and incorporated to the process in the future. These include the use of L1 norm in Least Square Adjustment, which could help to reduce the effect of blunders.

\section{Conclusions}

Videogrammetry through smartphones is a useful tool to create 3D models for cranial deformations analysis as well as for other medical applications. The ellipsoid fitting approach is a novel approach to evaluate the deformation in an objective, repeatable and automatic manner, which provides information for the whole head.

The methodology has shown an approximate repeatability error of $3 \mathrm{~mm}$. This accuracy is comparable with methods traditionally used to evaluate this type of deformation such as calliper. Furthermore, this methodology provides a larger quantity of information as 
it shows the deformation for every single point of the model.

As the methodology is still in development, there are real possibilities to increase accuracy by improving the definition of the modelled area and using improved adjustment methods that are less affected by noise.

\section{Acknowledgements}

This work was supported by Subprogram C (No. C10) for the development of coordinated actions between the UPV and the IIS La Fe.

\section{References}

ALDRIDGE, K., BOYADJIEV, S.A., CAPONE, G.T., DELEON, V.B. and RICHTSMEIER, J.T., 2005. Precision and error of three-dimensional phenotypic measures acquired from 3dMD photogrammetric images', American Journal of Medical Genetics, 138 A(3), pp. 247-253. doi: 10.1002/ajmg.a.30959.

BARBERO-GARCÍA, I., LERMA, J.L., MARQUÉS-MATEU, Á. ans MIRANDA, P., 2017. Low-Cost Smartphone-Based Photogrammetry for the Analysis of Cranial Deformation in Infants, World Neurosurgery, 102, pp. 545-554. doi: 10.1016/j.wneu.2017.03.015.

BEKTAS, S., 2014. Orthogonal distance from an ellipsoid, Boletim de Ciências Geodésicas, 20(4), pp. 970-983. doi: 10.1590/S1982-21702014000400053.

BEKTAS, S., 2015. Least square fitting of ellipsoid using orthogonal distances, Boletim de Ciências Geodésicas. Universidade Federal do Paraná, 21(2), pp. 329-339. doi: 10.1590/S1982-21702015000200019.

MOGHADDAM, M.B., BROWN, T.M., CLAUSEN, A., DASILVA, T., HO, E. and FORREST, C.R., 2014. Outcome analysis after helmet therapy using 3D photogrammetry in patients with deformational plagiocephaly: The role of root mean square, Journal of Plastic, Reconstructive and Aesthetic Surgery. Elsevier Ltd, 67(2), pp. 159-165. doi: 10.1016/j.bjps.2013.09.036.

PATHMANABAN, O.N., BURKE, K.A., LEACH, P., THORNE, J. and KAMALY-ASL, I.D., 2016. Non-synostotic posterior brachycephaly with hindbrain herniation, World Neurosurgery. doi: 10.1016/j.wneu.2016.10.027.

PLANK, L.H., GIAVEDONI, B., LOMBARDO, J.R., GEIL, M.D. and REISNER, A., 2006. Comparison of infant head shape changes in deformational plagiocephaly following treatment with a cranial remolding orthosis using a noninvasive laser shape digitizer. The Journal of craniofacial surgery, 17(6), pp. 1084-1091. doi: 10.1097/01.scs.0000244920.07383.85.

SCHAAF, H., PONS-KUEHNEMANN, J., MALIK, C.Y., STRECKBEIN, P., PREUSS, M., HOWALDT, H.P. and WILBRAND, J.F., 2010. Accuracy of three-dimensional photogrammetric images in non-synostotic cranial deformities, Neuropediatrics, 41(1), pp. 24-29. doi: 10.1055/s-0030-1255060.

SIEGENTHALER, M.H., 2015. Methods to Diagnose, Classify, and Monitor Infantile Deformational Plagiocephaly and Brachycephaly: A Narrative Review, Journal of Chiropractic Medicine. National University of Health Sciences, 14(3), pp. 191-204. doi: 10.1016/j.jcm.2015.05.003.

SZPALSKI, C., WEICHMAN, K., SAGEBIN, F. and WARREN, S.M., 2011. Need for standard outcome reporting systems in craniosynostosis, Neurosurgical focus, 31(2), p. E1. doi: 10.3171/2011.6.FOCUS1192. 